\title{
The RNA modification database
}

\author{
Pamela F. Crain ${ }^{1}$ and James A. McCloskey ${ }^{1,2, *}$
}

Departments of ${ }^{1}$ Medicinal Chemistry and ${ }^{2}$ Biochemistry, University of Utah, Salt Lake City, UT 84112, USA

Received October 12, 1995; Accepted October 13, 1995

\begin{abstract}
The RNA modification database provides a comprehensive listing of post-transcriptionally modified nucleosides from RNA and is maintained as an updated version of the initial printed report. Information provided includes: type(s) of RNA in which found and phylogenetic distribution; common chemical names and symbols; Chemical Abstracts registry numbers and index names; chemical structures; initial literature citations for structural characterization or occurrence and chemical synthesis. The data are available through the World Wide Web, anonymous ftp or from the authors in printed form.
\end{abstract}

\section{INTRODUCTION}

Both the structural diversity and extent of post-transcriptional modification in RNA is remarkable, with more than 93 different nucleosides presently known in all types of RNA (1). The discovery of new modified nucleosides as well as increasing knowledge of the array of functional roles of modification, based largely on extensive studies of tRNA (2-4), mandates a need for a comprehensive database of RNA nucleosides. The RNA Modification Database is maintained as an extension of the initial version published in mid-1994 (1). The database consists of all RNA-derived ribonucleosides of known structure, including those from established sequence positions, as well as those detected or characterized from hydrolysates of RNA. The information provided permits access to the modified nucleoside literature through provision of both computer searchable Chemical Abstracts registry numbers and key literature citations.

The reader is referred to the earlier publication (1) or to the text portion of the present database for comments or discussion of the following topics: usage of modified nucleoside symbols and notations; accuracy of assignments in the early literature; problems associated with modification assignments in rRNA; exclusion from the database collection of nucleoside degradation products and of erroneous structures or distributions in literature reports.

The authors invite comments concerning new entries, errors or omissions and on the format presently used for electronic access to the database. The email address for this purpose is: rnamods@ecclab.med.utah.edu

\section{DESCRIPTION OF THE DATABASE}

In general each nucleoside file consists of the following.

Type of RNA in which found: tRNA (presently consisting of 79 nucleosides), rRNA (28), mRNA (12), snRNA (11), chromosomal RNA (two) and other RNAs (one).

Common chemical names and symbols.

Chemical Abstracts registry numbers for the ribonucleoside and corresponding base if assigned.

Chemical Abstracts index name, which in some cases includes stereochemical information not shown in the database chemical structure.

Chemical structure of nucleoside.

Phylogenetic occurrence of the RNA in which found, archaea (archaebacteria), (eu)bacteria or eukarya, and the corresponding literature citations for each. Ribosomal RNA entries are further distinguished by RNA size, e.g. 16S, $28 \mathrm{~S}$.

Literature citation to structure assignment of the nucleoside.

Literature citation to the first reported chemical synthesis of the nucleoside or, in limited cases, of the base. Subsequent reports of synthesis, which often include refinements, can be accessed effectively by computer through the Chemical Abstracts registry numbers.

Comments on any of the above entries, including additional literature citations or alternative nomenclature.

Access to individual nucleoside files within the database can be made through any of four entry points: common name; abbreviation symbol; RNA type; chemical structure (displayed graphically via WWW format). An example of the information contained in a single nucleoside file is shown in Figure 1.

The database currently (October, 1995) contains 94 modified ribonucleoside entries, distributed by RNA type and phylogenetic source as shown in Table 1.

\section{AVAILABILITY}

Starting in late 1995 the modification database will be accessible as follows:

Anonymous ftp (ftp://medlib.med.utah.edu/library/RNAmods);

World Wide Web (http://www-medlib.med.utah.edu/RNAmods/ RNAmods.html);

In printed form from either author at 311A Skaggs Hall, University of Utah, Salt Lake City, UT 84112, USA (email rnamods@ecclab.med.utah.edu).

\footnotetext{
* To whom correspondence should be addressed
} 


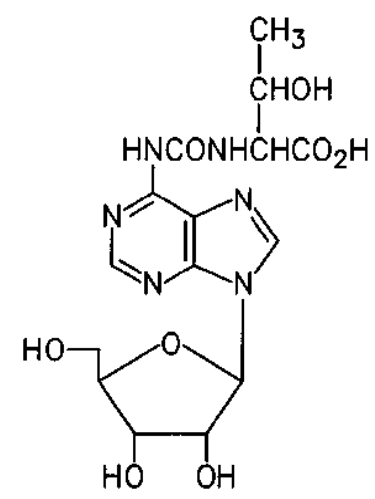

Symbol $t^{6} \mathrm{~A}$

Common name: $\mathrm{N}^{6}$-threonlycarbamoyladenosine

RNA type: tRNA

Phylogenetic sources: archaea, bacteria, eukarya

Structure: ref. 1

Synthesis: ref, 2

CA registry numbers: ribonucleoside $24719-82-2$

$$
\text { base } \quad 33422-66-1
$$

CA index name: L-threonine, $\mathrm{N}-[[(9-\beta-\mathrm{D}-\mathrm{ribofuranosyl}-9 H$-purin-6-yl) amino]carbonyl]-

Comment: ref. 1 reports characterization of the base of this nucleoside.

The L-configuration for threonine in t6A was established in ref. 2.

References

1. Schweizer, M.P., Chheda, G.B., Baczynskyj, L. and Hall, R.H.

(1969) Biochemistry, 8, 3283-3289.

2. Chheda, G.B. and Hong, C.I. (1971) J. Med. Chem., 14, 748-753.

Figure 1. Database record for the modified nucleoside $N^{6}$-threonylcarbamoyladenosine

Table 1. Modified ribonucleoside distributions in RNA

\begin{tabular}{llll}
\hline RNA & $\begin{array}{l}\text { Source } \\
\text { Archaea }\end{array}$ & (eu)Bacteria & Eukarya \\
\hline tRNA & 36 & 42 & 46 \\
rRNA & & $1^{\mathrm{a}}$ & $4^{\mathrm{a}}$ \\
SSU & 3 & 8 & 18 \\
LSU & & 14 & 12 \\
5S & 3 & & 1 \\
$5.8 \mathrm{~S}$ & & & 5 \\
mRNA & & & 12 \\
snRNA & & & 11 \\
Chromosomal RNA & & & 2 \\
Other small RNA & & & 1 \\
\hline
\end{tabular}

aSubunit origin not shown or is reported in a mixture of SSU and LSU rRNAs.

\section{ACKNOWLEDGEMENTS}

We are grateful to Y. Zhang, S. C. Pomerantz and N. Lombardo for assistance in implementing the electronic version of the database. Maintenance of the database is supported by NIH grant GM 29812.

\section{REFERENCES}

1 Limbach,P.A., Crain,P.F. and McCloskey,J.A. (1994) Nucleic Acids Res., 22, 2183-2196.

2 Björk,G.R., Ericksson,J.U., Gustafsson,C.E.D., Hagervall,T.G., Jönsson,Y.H. and Wikström,P.M. (1987) Annu. Rev. Biochem., 56, 263-287.

3 Björk,G.R. (1992) In Hatfield,D.L., Lee,B.J. and Pirtle,R.M. (eds), Transfer RNA in Protein Synthesis. CRC Press, Boca Raton, FL, pp. 23-85.

4 Yokoyama,S. and Nishimura,S. (1995) In Söll,D. and RajBhandary,U.L. (eds), tRNA Structure, Biosynthesis, and Function. American Society for Microbiology, Washington, DC, pp. 207-223. 